\title{
Influence of Synthesis pH on Textural Properties of Carbon Xerogels as Supports for Pt/CXs Catalysts for Direct Methanol Fuel Cells
}

\author{
C. Alegre, M. E. Gálvez, D. Sebastián, R. Moliner, and M. J. Lázaro \\ Instituto de Carboquímica (CSIC), Miguel Luesma Castán 4, 50018 Zaragoza, Spain \\ Correspondence should be addressed to M. J. Lázaro, mlazaro@icb.csic.es
}

Received 1 May 2011; Revised 4 September 2011; Accepted 19 September 2011

Academic Editor: Elena Pastor Tejera

Copyright ( $) 2012$ C. Alegre et al. This is an open access article distributed under the Creative Commons Attribution License, which permits unrestricted use, distribution, and reproduction in any medium, provided the original work is properly cited.

\begin{abstract}
Carbon xerogels (CXs) have been prepared by polycondensation of resorcinol and formaldehyde. Two synthesis pHs were studied in order to evaluate its influence on the electrochemical behaviour of Pt catalysts supported on previous carbon xerogels, synthesized by conventional impregnation method. Catalysts were also synthesized over a commercial carbon black (Vulcan-XC$72 \mathrm{R}$ ) for comparison purposes. Characterization techniques included nitrogen physisorption, scanning electron microscopy, and $\mathrm{X}$-ray diffraction. Catalysts electrochemical activity towards the oxidation of carbon monoxide and methanol was studied by cyclic voltammetry and chronoamperometry to establish the effect of the carbon support on the catalysts performance. Commercial $\mathrm{Pt} / \mathrm{C}$ catalyst (E-TEK) was analyzed for comparison purposes. It was observed that the more developed and mesopore-enriched porous structure of the carbon xerogel synthesized at a higher initial $\mathrm{pH}$ resulted in an optimal utilization of the active phase and in an enhanced and promising catalytic activity in the electrooxidation of methanol, in comparison with commercial catalysts.
\end{abstract}

\section{Introduction}

One of the main challenges nowadays in polymer-electrolyte fuel cell technology is the optimization of the catalytic systems employed in anode (fuel oxidation) and cathode (oxygen reduction), towards the enhancement of their catalytic activity and durability, at each time lower noble metalnormally $\mathrm{Pt}$ - loads. In the case of the anode of direct methanol fuel cells (DMFCs), the detailed mechanism of methanol oxidation has been elucidated during the last decades using a variety of experimental procedures, and several reviews can serve as a reference for the reader $[1,2]$. Basically, the electrochemical oxidation of methanol on Pt involves several intermediate steps such as dehydrogenation, CO-like species chemisorption, $\mathrm{OH}$ ( or $\mathrm{H}_{2} \mathrm{O}$ ) species adsorption, chemical interaction between adsorbed $\mathrm{CO}$ and $\mathrm{OH}$ compounds, and $\mathrm{CO}_{2}$ evolution. The catalytic activity strongly depends on the metallic composition (it is well known that the presence of a second metal like $\mathrm{Ru}$ or Sn considerably enhances the $\mathrm{OH}$ adsorption and, consequently, the electrocatalytic activity), the particle size, the metallic surface structure, and the metalsupport interaction [1-3].
Employing high-surface area carbon supports has been regarded as one of the most plausible options for achieving an optimal utilization of the active phase. Thus, in the last decade, an increasing number of publications report the synthesis and use of advanced carbon supports for fuel cell systems, such as carbon nanotubes $[4,5]$, carbon nanofibers $[6,7]$, ordered mesoporous carbons [8], and carbon xerogels and aerogels $[4,8-13]$, which can lead to more stable, highly active catalysts, at lower platinum loadings $\left(<0.1 \mathrm{mg} \cdot \mathrm{cm}^{-2}\right)$ than in the case of using conventional carbon black supports, leading therefore to lower catalyst cost [14]. In the preparation of carbon-supported catalysts, textural properties of the support can be properly adjusted in order to overcome mass transfer limitations while favouring an adequate dispersion of the active phase. This fact becomes especially significant in the case of the preparation of catalysts for electrochemical applications; their electrochemical properties may become strongly dependent on their final textural features, with adequate specific surface area and abundance of mesopores in the pore size range of $20-40 \mathrm{~nm}$, resulting fundamental for a highly accessible catalytic surface area [15]. 
Since their introduction by Pekala in 1989 [16], resorcinol-formaldehyde aqueous gels have received considerable attention, due to the possibility of fine-tuning their textural properties by adequately modifying different parameters involved in their preparation [17]. In this way, it is possible to obtain a wide variety of materials with different properties which can be used in a wide range of applications [18]. Apart from this fact, these synthetic carbon materials possess high purity, and, moreover, whereas carbon blacks are constituted of aggregates connected through van der Waals bonds, carbon gels display monolithic structures at the micrometer scale, and, as a consequence, the pore texture of a carbon gel micromonolith remains identical in the catalytic layer of a membrane-electrode assembly $[14,19]$. In previous studies $[14,19]$, PEMFCs cathodes were prepared from Pt catalyst supported on carbon aerogels and xerogels. The results obtained clearly evidenced that an adequate choice of the carbon pore texture can in fact lead to a significant decrease of the diffusion-induced potential losses. Liu and Creager [20] have recently reported as well evidence of lower mass transfer resistance in Pt-loaded carbon xerogels vis-à-vis the same electrocatalyst prepared using carbon black Vulcan XC$72 \mathrm{R}$ as support.

Arbizzani et al. [15] studied the specific catalytic activity of DMFC anodes based on PtRu catalysts deposited by chemical and electrochemical route on mesoporous cryoand xerogel carbons. Their results were compared with those obtained with PtRu supported on Vulcan, being the specific catalytic activity more than double when Vulcan is substituted by former carbons.

Job et al. [21] also synthesized highly mesoporous carbon via sol-gel condensation of resorcinol and formaldehyde. Electrooxidation of methanol in alkaline electrolyte was carried out using $\mathrm{Pt}$ and $\mathrm{PtNi}$ catalysts supported on highly mesoporous carbon xerogels. The electrocatalytic tests showed better performance of the catalysts when impregnated on this kind of carbon support.

In a more recent work [5], the same group prepared multiwalled carbon nanotubes and high surface area mesoporous carbon xerogel and used them as supports for monometallic $\mathrm{Pt}$ and bimetallic PtRu catalysts. In order to assess the influence of the oxygen surface groups of the support, the mesoporous carbon xerogel was also oxidized with diluted oxygen before impregnation. A remarkable increase in the activity was observed when the PtRu catalysts were supported on the oxidized xerogel. This effect was explained in terms of the metal oxidation state. It was shown that the oxidized support helps to maintain the metals in the metallic state, as required for the electrooxidation of methanol.

However, carbon gels have also been tested as carbon supports in several applications different from the field of electrocatalysis. For example, Job et al. [9] prepared $\mathrm{Pt} / \mathrm{C}$ catalysts by impregnation of three xerogels possessing various pore textures. They observed that the specific catalytic activity measured towards benzene hydrogenation was 410 times higher in the presence of the carbon-xerogelsupported catalysts than the one determined for analogous active charcoal-supported ones. This enhanced catalytic activity was attributed to higher Pt dispersion on the carbon surface, due to the abundant presence of large mesopores and wide mesopores in the carbon xerogel pore structure, which in the end facilitated its impregnation with the precursor of the active phase.

Carbon gels preparation comprises several steps, basically, (i) sol-gel synthesis and gel curing, (ii) drying, for removing the excess solvent, and (iii) carbonization of the organic gel. Carbon aerogels differ from carbon xerogels in the drying procedure applied in each case. While supercritical drying is used to synthesize carbon aerogels, carbon xerogels are prepared using conventional evaporative drying. This last option results in the shrinkage of the initial porous structure of the gel $[22,23]$, but its consequences can be really advantageous, depending on the final application of the carbon material. Furthermore, synthesis costs are also substantially reduced by means of choosing evaporative drying. Carbon xerogels possessing microporous, micromesoporous, to micro-macroporous structures can be produced by varying the morphologies of the primary particles that compose them, the degree of interconnectivity among primary particles, and by means of controlling gel structure shrinkage during drying, which is as well determined by the original structure of the organic gel. Resorcinol to formaldehyde molar ratio, kind and amount of catalyst used, solvent, dilution, and $\mathrm{pH}$ have a decisive influence in final gel properties. With respect to $\mathrm{pH}$ effect on the porosity of carbon gels, Mahata et al. [24] prepared carbon xerogels at two different $\mathrm{pH}$ values, 5.5 and 6 , observing that the materials prepared at the lower $\mathrm{pH}$ values possessed considerably higher mesopore area but lower average pore diameter. Lin and Ritter [25] previously reported similar observations. They prepared carbon xerogels at $\mathrm{pH}$ values between 5.5 and 7.0, observing, that as the $\mathrm{pH}$ decreased from 7.0 to 6.5 , the surface area increased sharply from 0 to $600 \mathrm{~m}^{2} \cdot \mathrm{g}^{-1}$, then remained constant over the $\mathrm{pH}$ range from 6.5 to 5.5 . In contrast, the pore volume increased almost linearly as the $\mathrm{pH}$ decreased between 7.0 and 5.7, and then remained constant at around $0.8 \mathrm{~cm}^{3} \cdot \mathrm{g}^{-1}$ over the $\mathrm{pH}$ range from 5.7 to 5.5 . These results indicate that the increase in the pore volume that occurred with a decrease in the $\mathrm{pH}$ from 6.5 to 5.5 corresponded to the creation of larger pores which did not contribute much to the surface area. They also observed that higher $\mathrm{pH}$ values led to carbon gels with a weaker pore structure which collapsed easily after drying and pyrolysis. They stated that higher $\mathrm{pH}$ hindered the condensation reaction leading to less cross-linking of the structures and resulting in a much weaker gel structure than at lower $\mathrm{pH}$. A few years later, Zanto et al. [23] claimed the opposite, comparing carbon aerogels and xerogels synthesized at $\mathrm{pH}$ values of 5.5 and 7.0. The highest $\mathrm{pH}$ corresponded to the highest development of surface area and porosity. These authors explained this fact by stating, that at their higher $\mathrm{pH}$ setting, cross-linking of the already formed clusters occurred to a greater extent due to lower concentration of protons in the media, what resulted in a more porous polymeric structure. Zubizarreta et al. [26] noticed that the time required for gelation, curing, and drying of their organic gels depended on the $\mathrm{pH}$ of the initial solution. This parameter also influenced the structure of the materials 
after drying, being less compact at the lowest $\mathrm{pH}$ values employed. In consequence, surface area and pore volume of the carbon gels decreased with increasing synthesis $\mathrm{pH}$. Job and coworkers reported as well the strong influence that the $\mathrm{pH}$ of the solution in the synthesis of a carbon xerogel exerts on the final properties of these carbon materials [27]. As $\mathrm{pH}$ was increased from 5.45 to 7.35 , carbon gels evolved from micro-macroporous to exclusively microporous materials, that is, pore size distribution becoming narrower at higher $\mathrm{pHs}$, whereas surface area passed through a maximum at a $\mathrm{pH}$ of 6.50. However, these series of published works also evidence that there is no general agreement on the influence of this parameter in controlling the carbon gel final structure and that this might depend as well on the rest of the parameters involved in the gel synthesis and, in general, on the experimental procedure and setup used in each case.

In the present paper, mesoporous carbon xerogels have been synthesized at two $\mathrm{pH}$ values: 5.5 and 5.8, with the aim of evaluating its influence on the carbonaceous textural properties and, in turn, on the electrochemical behaviour of Pt-supported electrocatalysts. Although in recent years, $\mathrm{PtRu}, \mathrm{PtSn}$, and other Pt alloys have replaced Pt for the preparation of anodic catalysts, due to their enhanced performance and resistance towards CO poisoning [25-28], Pt was exclusively used as active metal through the present work in order to simplify the catalytic system. In this sense, this is a preliminary study focused on the evaluation of the particular influence of the carbon support in the catalyst activity, independently of the influence of other parameters such as $\mathrm{Pt}: \mathrm{M}(\mathrm{Ru}, \mathrm{Sn}$, etc.) atomic ratio, oxidation state, or the interaction between the bimetallic sites. Future works will comprise the introduction of bimetallic systems on the best support. Commercial Pt-supported catalyst (E-TEK) has also been studied for comparison. Moreover, in order to compare the results obtained using the synthesised carbon xerogels as supports, a catalyst was prepared using a commercial carbon black (Vulcan-XC-72 R) instead. Voltamperometric studies towards carbon monoxide and methanol oxidation were carried out in order to analyze the influence of the carbon support on the electrochemical behaviour of Pt catalysts [29].

\section{Experimental}

2.1. Synthesis of Carbon Xerogels. Resorcinol (1,3-dihydroxybenzoic acid)-formaldehyde organic gels were synthesized following the procedure described in detail in [27]. $9.91 \mathrm{~g}$ of resorcinol $(99 \% \mathrm{Vol})$ were first mixed with $18.8 \mathrm{~mL}$ of deionised water under magnetic stirring and poured into sealable flasks. After dissolution, the $\mathrm{pH}$ value was generally close to 2 and was first increased close to the chosen value (5.5 and 5.8) by addition of concentrated sodium hydroxide solution ( 5 and $2 \mathrm{~N}$ solutions were used). Afterwards $13.5 \mathrm{~mL}$ of formaldehyde solution (Aldrich, 37\% wt. in water, stabilized by $10-15 \%$ wt. methanol) were added to the mixture (resorcinol/formaldehyde ratio was 0.5 ), and the $\mathrm{pH}$ value was then finally adjusted by addition of diluted sodium hydroxide solution $(0.5 \mathrm{~N})$. The use of three different alkaline solutions of various concentrations enabled us to minimize the amount of water added during $\mathrm{pH}$ adjustment.

Gelation was performed at $85^{\circ} \mathrm{C}$ in an oven. The obtained aqueous gels were then dried without any pretreatment, at $65^{\circ} \mathrm{C}$ for $5 \mathrm{~h}$, and then, temperature was risen up to $110^{\circ} \mathrm{C}$ and held for another $5 \mathrm{~h}$, as described elsewhere [25]. After drying, the gels were pyrolyzed at $800^{\circ} \mathrm{C}$ under nitrogen flow in a tubular oven, following the heating pattern described elsewhere [27]. Carbon xerogels obtained were named: CX_550, the one synthesized at $\mathrm{pH}=5.5$, and CX_580, in the case of adjusting to $\mathrm{pH}=5.8$ during its synthesis.

2.2. Pt Catalysts Synthesis. Pt was deposited on carbon xerogels by impregnation and reduction with sodium borohydride [2]. The amount of metallic precursors was adjusted in order to obtain a final nominal metal loading of $20 \% \mathrm{w} / \mathrm{w}$. An aqueous solution of $\mathrm{H}_{2} \mathrm{PtCl}_{6}$ (Sigma-Aldrich) was slowly added into a dispersion of carbon xerogel or carbon black in ultrapure water under sonication. $\mathrm{pH}$ was adjusted to 5 with a $5 \mathrm{~N} \mathrm{NaOH}$ solution. The loaded metal was reduced by addition of sodium borohydride, maintaining temperature around $18^{\circ} \mathrm{C}$. Subsequently, catalysts were filtered and thoroughly washed with ultrapure water and dried overnight at $60^{\circ} \mathrm{C}$.

\subsection{Carbon Xerogels and Catalysts Textural and Morphological} Characterization. The textural and morphological features of the synthesized carbon xerogels were determined by means of nitrogen physisorption at $-196^{\circ} \mathrm{C}$ (Micromeritics ASAP 2020) and scanning electron microscopy (SEM, Hitachi S-3400 N). Textural properties such as specific surface area, pore volume, and pore size distribution were calculated from each corresponding nitrogen adsorptiondesorption isotherms applying the Brunauer-Emmett-Teller (BET) equation, Barrett-Joyner-Halenda (BJH), and $t$-plot methods.

SEM combined with energy dispersive X-ray spectroscopy (SEM-EDX) was used to determine the amount of metal deposited. An analyzer EDX Röntec XFlash de Si(Li) was employed with this purpose. Catalysts were as well characterized by X-ray diffraction (XRD), using a Bruker AXS D8 Advance diffractometer, with a $\theta-\theta$ configuration and using $\mathrm{Cu}-\mathrm{K} \alpha$ radiation.

2.4. Electrochemical Characterization. Electrochemical characterization has proven to be of key importance in determining the electrocatalytic activity of these materials [29, 30]. Catalysts electrochemical activity towards the oxidation of carbon monoxide and methanol was studied by cyclic voltammetry and chronoamperometry at room temperature as in previous works $[6,8,31]$. A cell with a three-electrode assembly at room temperature and an AUTOLAB potentiostat-galvanostat were used to carry out the electrochemical characterization. The counter electrode consisted on a pyrolytic graphite rod, while the reference electrode was a reversible hydrogen electrode (RHE). Therefore, all potentials in the text are referred to the latter. The working electrode consisted of a pyrolytic graphite disk $(7 \mathrm{~mm})$ with 
a thin layer of the electrocatalyst under study deposited onto it. For the preparation of this layer, an aqueous suspension consisting of $2 \mathrm{mg}$ of $\mathrm{Pt} / \mathrm{C}$ catalyst was obtained by ultrasonically dispersing it in Nafion solution $10 \%$ wt. $(15 \mu \mathrm{L})$ and ultrapure water $(500 \mu \mathrm{L})$ (Millipore). Subsequently an aliquot of $40 \mu \mathrm{L}$ of the dispersed suspension was deposited on top of the graphite disk $(7 \mathrm{~mm})$ and dried under inert atmosphere prior to its use.

After preparation, the electrode was immersed into deaerated $0.5 \mathrm{M} \mathrm{H}_{2} \mathrm{SO}_{4}$ electrolyte, prepared from high purity reagents (Merck) and ultrapure water (Milli-Q). The electrolyte was saturated with pure $\mathrm{N}_{2}$ or CO (99.997\%, Air Liquide), depending on the experiments. Prior to the electrochemical characterization, the electrode was subjected to potential cycling between 0.05 and $1.10 \mathrm{~V}$ versus RHE at a scan rate of $500 \mathrm{mV} \cdot \mathrm{s}^{-1}$ until a stable voltammogram in the base electrolyte $\left(0.5 \mathrm{M} \mathrm{H}_{2} \mathrm{SO}_{4}\right)$ was obtained. $\mathrm{CO}$ stripping voltammograms were obtained after bubbling this gas in the cell for $10 \mathrm{~min}$ at $0.20 \mathrm{~V}$ versus RHE, followed by nitrogen purging to remove the excess of $\mathrm{CO}$. The admission potential was selected considering that, for this value, maximum adsorbate coverage is achieved for $\mathrm{CO}$ adsorption on $\mathrm{Pt}$. Afterwards, potential cycling between $0.05 \mathrm{~V}$ and $1.10 \mathrm{~V}$ versus $\mathrm{RHE}$ at $20 \mathrm{mV} \cdot \mathrm{s}^{-1}$ was carried out to follow CO oxidation. Electrochemical Pt active areas were determined from the integration of the current involved in the oxidation of a CO monolayer, taking into account that CO linearly adsorbs on $\mathrm{Pt}$ and assuming $420 \mu \mathrm{C} / \mathrm{cm}^{2}$ involved in the oxidation process. Current values were normalized with respect to the electroactive area.

Cyclic voltammograms for the electrooxidation of methanol were carried out in a $2 \mathrm{M} \mathrm{CH} 3 \mathrm{OH}+0.5 \mathrm{M} \mathrm{H}_{2} \mathrm{SO}_{4}$ solution, at scan rate of $20 \mathrm{mV} \cdot \mathrm{s}^{-1}$, between 0.05 and $1.10 \mathrm{~V}$ versus RHE, and current was normalized with respect to each catalyst electroactive area.

Chronoamperometries were performed at $0.60 \mathrm{~V}$ versus $\mathrm{RHE}$ in a $2 \mathrm{M} \mathrm{CH} 3 \mathrm{OH}+0.5 \mathrm{M} \mathrm{H}_{2} \mathrm{SO}_{4}$ solution, in order to evaluate the evolution of the electrocatalytic activity with time of the prepared catalysts in the electrooxidation of methanol. All the experiments were carried out at room temperature $\left(25 \pm 1^{\circ} \mathrm{C}\right)$, and current was normalized with respect to each catalyst electroactive area.

\section{Results and Discussion}

3.1. Influence of Synthesis $p H$ in Carbon Xerogel Textural Features. Surface areas and pore volumes (total, mesopore and micropore) of the synthesized carbon xerogels and the commercial carbon black (Vulcan) determined from nitrogen physisorption isotherms are shown in Table 1. High values of surface area, 436 and $493 \mathrm{~m}^{2} / \mathrm{g}$, were measured for the carbon xerogels CX_550 and CX_580, respectively, considerably higher than the one obtained for Vulcan XC$72 \mathrm{R}, 223 \mathrm{~m}^{2} / \mathrm{g}$. Total pore volume in the case of the carbon xerogel synthesized at the highest $\mathrm{pH}, \mathrm{CX} \_580,1.09 \mathrm{~cm}^{3} / \mathrm{g}$, is also noticeably higher than for the carbon black Vulcan and carbon xerogel CX_550, $0.47 \mathrm{~cm}^{3} / \mathrm{g}$. The $\mathrm{pH}$ of the initial solution clearly plays a definitive roll in the development
TABLE 1: Carbon supports (xerogels and carbon black) textural properties.

\begin{tabular}{lcccc}
\hline Sample & $\begin{array}{c}\text { Surface } \\
\text { area, } \mathrm{S}_{\text {BET }} \\
\left(\mathrm{m}^{2} \mathrm{~g}^{-1}\right)\end{array}$ & $\begin{array}{c}\text { Total pore } \\
\text { volume } \\
\left(\mathrm{cm}^{3} \mathrm{~g}^{-1}\right)\end{array}$ & $\begin{array}{c}\text { Mesopore } \\
\text { volume } \\
\mathrm{V}_{\text {meso,BJH }} \\
\left(\mathrm{cm}^{3} \mathrm{~g}^{-1}\right)\end{array}$ & $\begin{array}{c}\text { Micropore } \\
\text { volume } \\
\mathrm{V}_{\text {micro, t-plot }} \\
\left(\mathrm{cm}^{3} \mathrm{~g}^{-1}\right)\end{array}$ \\
\hline CX_550 & 436 & 0.47 & 0.25 & 0.21 \\
CX_580 & 493 & 1.09 & 0.87 & 0.20 \\
Vulcan & 224 & 0.47 & 0.41 & 0.04 \\
\hline
\end{tabular}

of porosity: a slight $\mathrm{pH}$ increase led to an almost two-fold higher pore volume and about $10 \%$ higher surface area. The main difference between CX_550 and CX_580 is the total pore volume which is more than double for the latter $\left(1.09 \mathrm{~cm}^{3} / \mathrm{g}\right.$ for CX_580) than for the former $\left(0.47 \mathrm{~cm}^{3} / \mathrm{g}\right.$ for CX_550). Mesopore volume values reflect that these are the pores which are preferentially formed when using a higher solution $\mathrm{pH}$. In fact, a 3-fold increase in mesopore volume value can be observed when comparing CX_580 to CX_550, while it almost doubles the value determined for Vulcan carbon black. In the case of the synthesized carbon xerogels, micropore volume remains constant, independently of the synthesis $\mathrm{pH}$, and, in any case, substantially higher than for Vulcan carbon black.

With respect to the morphology of carbon xerogels, SEM images (Figure 1) show that carbon xerogel synthesized at the lowest $\mathrm{pH}$ value of 5.5, CX_550, is formed by small polymer particles that are interconnected with large necks giving the gel a fibrous appearance. The appearance of the carbon xerogel synthesized at the highest pH, CX_580, differs slightly from the one observed for CX_550. At higher $\mathrm{pH}$ carbon gel structure looks less defined, more compact, and conformed by smaller polymeric particles pointing either to a higher degree of cross-linking, as suggested by Zanto et al. [23] or even due to a partial collapse of porosity during drying and pyrolysis, as stated by Lin and Ritter [25].

3.2. Pt/Carbon Xerogel Catalysts Physico-Chemical Characterization. Pt catalysts supported on the synthesized carbon xerogels were characterized by SEM-EDX and XRD. Their properties are summarized in Table 2. SEM-EDX analyses were carried out to determine the metal concentration in the electrocatalysts. Pt concentrations around 17-18\% weight were obtained, close to $20 \%$ nominal loading. XRD patterns (Figure 2) show the typical reflectances of the face-centered cubic structure of platinum. Pt crystallite sizes obtained from the 220 peak in the XRD diffractograms (shown in Figure 2) using the Scherrer's equation are shown in Table 2.

Platinum supported on low pore volume carbon xerogel (Pt/CX_550) presents the highest crystal size of $6.2 \mathrm{~nm}$, whereas using the carbon xerogel with the high pore volume (CX_580) leads to a considerable decrease in crystal size to $4.5 \mathrm{~nm}$. This result highlights the importance of the support textural properties in the metallic crystal growth, where the impregnation of the carbon support can be impeded to a certain extent when there is a low presence of mesopores. Moreover, using Vulcan carbon black with a similar pore 


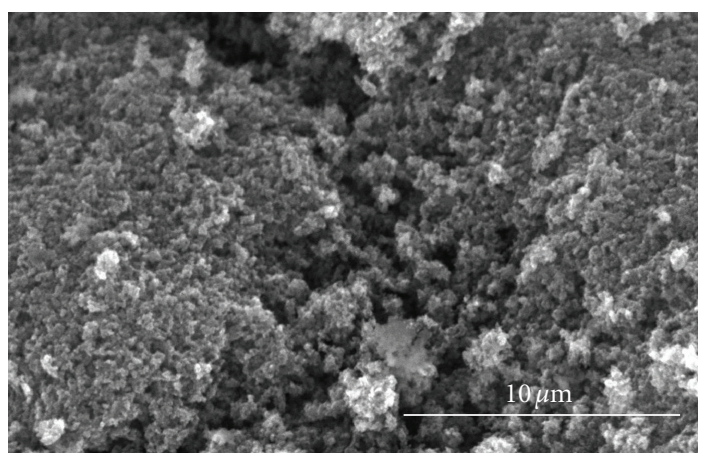

(a)

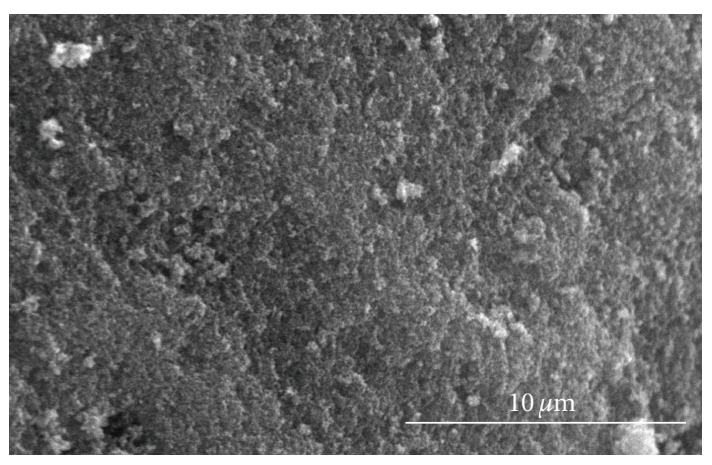

(b)

FIGURE 1: SEM micrographs of carbon xerogels: (a) CX_550; (b) CX_580.

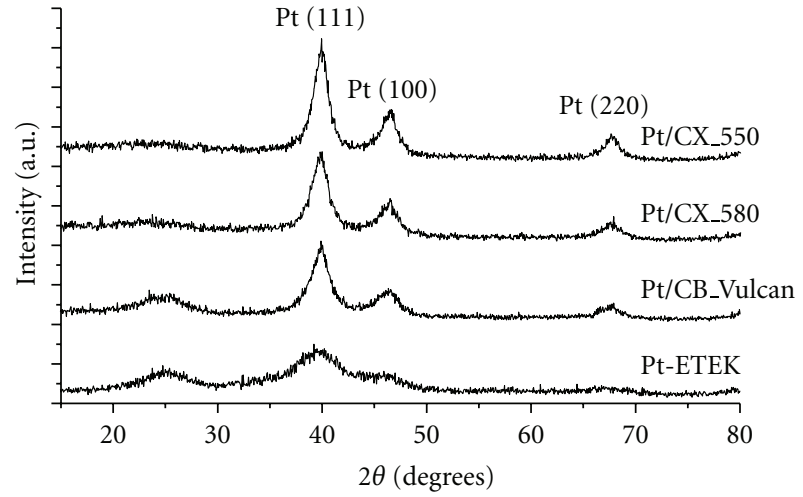

FIGURe 2: Diffractograms obtained by XRD for Pt catalysts assayed.

TABLE 2: Pt electrocatalysts properties.

\begin{tabular}{lcc}
\hline Sample & \% w/w Pt & Pt crystal size $(\mathrm{nm})$ \\
\hline Pt/CX_550 & 17 & 6.2 \\
Pt/CX_580 & 18 & 4.5 \\
Pt/CB_Vulcan & 17 & 4.0 \\
Pt-E-TEK & 18 & 3.0 \\
\hline
\end{tabular}

volume than CX_550 and half the surface area leads to a similar crystal size than the other CX_580, pointing out that not only textural properties are important but carbonaceous surface structure plays a role. On the other hand, the commercial catalyst (Pt-E-TEK) presents the lowest Pt crystal size of $3.0 \mathrm{~nm}$. These differences in crystal domain size of the active phase will result in different electrocatalytic behaviour, which is the main purpose of the next section.

\subsection{Electrochemical Characterization and Catalytic Activity.}

Pt catalysts supported on carbon xerogels were characterized by cyclic voltammetry $(\mathrm{CV})$. CO stripping was performed in order to establish the influence of the textural properties of the different supports in the electrochemical performance of each of the Pt catalysts towards CO electrooxidation. The electrooxidation of CO presents a strong dependence on the electrode surface state in terms of morphology and structure [32-34]. CO stripping voltammograms obtained are shown in Figure 3. The second cycles recorded after COstripping, which correspond to the voltammograms in the base electrolyte for clean surfaces, are also shown.

The $\mathrm{CO}_{\mathrm{ad}}$ oxidation peak for $\mathrm{Pt} / \mathrm{CX}$ catalysts was obtained around $0.82 \mathrm{~V}$ versus RHE, as for Pt-E-TEK, as reported in the literature for commercial catalysts [34]. Whereas the maximum occurs at similar potential values, slight differences are observed as a contribution at more negative potentials $(0.68-0.74 \mathrm{~V}$ versus RHE). The catalysts prepared by impregnation (Pt/CX_550, Pt/CX_580, and Pt/CB_Vulcan) present an onset potential at around $0.68 \mathrm{~V}$ versus RHE with a small shoulder not observed for Pt-E-TEK. This contribution to $\mathrm{CO}$ oxidation could be ascribed to the presence of certain surface arrangements in which $\mathrm{CO}$ is adsorbed with a slightly lower energy to platinum. Nevertheless, this contribution, although small compared to the peak observed at $0.82 \mathrm{~V}$ versus RHE, is independent of the crystal size (from $4.0 \mathrm{~nm}$ for CB_Vulcan up to $6.2 \mathrm{~nm}$ for CX_550), which is important to remark for the subsequent discussion about methanol oxidation. The charge observed at potential values higher than $0.9 \mathrm{~V}$ versus RHE could be attributed to the oxidation of the active phase or even the support to form oxygen functional groups [35], but, in any case, it represents a reversible process since the second cycle corresponds to the voltammogram in the base electrolyte, which means that a complete oxidation of the $\mathrm{CO}$ monolayer has been achieved in the first scan and the hydrogen adsorption-desorption region remains the same. Further spectroelectrochemical studies will be conducted and will serve to analyze these effects in deep.

To sum up, it can be concluded that, in this case, a different textural structure of the carbon xerogels does not seem to be a determinant factor for obtaining increased catalytic activity in the electrooxidation of $\mathrm{CO}$.

The analysis of the CVs also shows some differences in the current densities observed in the double-layer region $(0.4-0.6 \mathrm{~V})$, between the catalysts supported on carbon xerogels (Pt/CX_550 and Pt/CX_580) and on carbon blacks (Pt-E-TEK and Pt/CB_Vulcan). At $0.4 \mathrm{~V}$, the double-layer current density (obtained during the second voltammetric scan) is about 4 times higher for Pt/CXs. This fact implies 


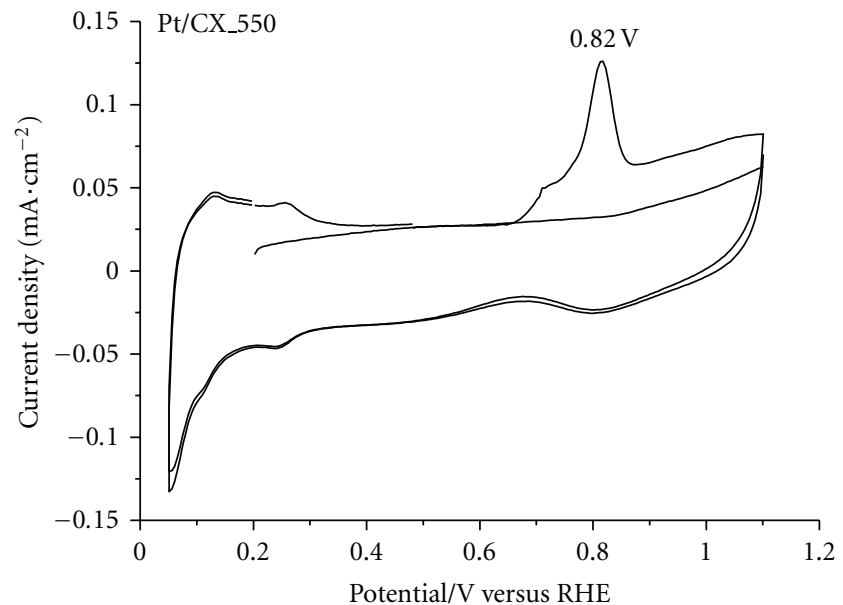

(a)

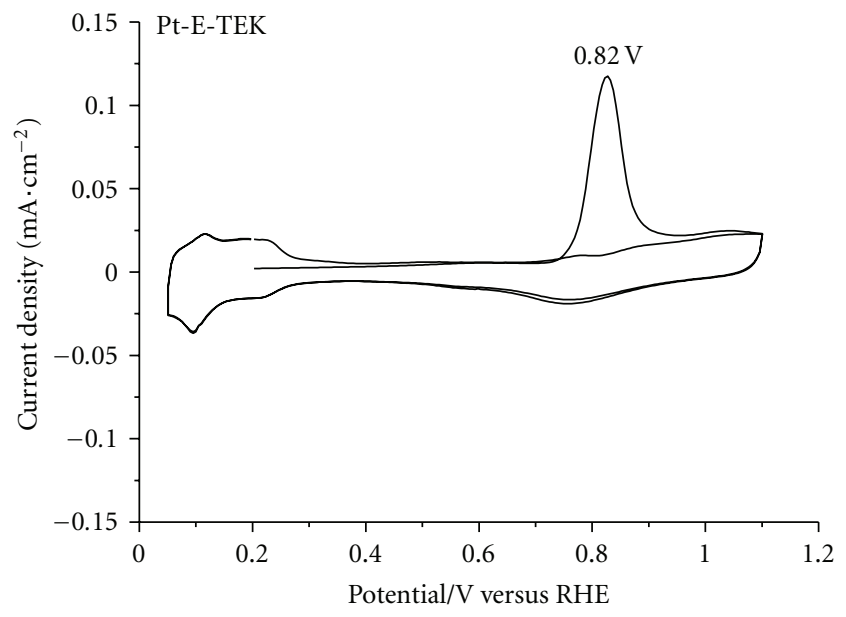

(c)

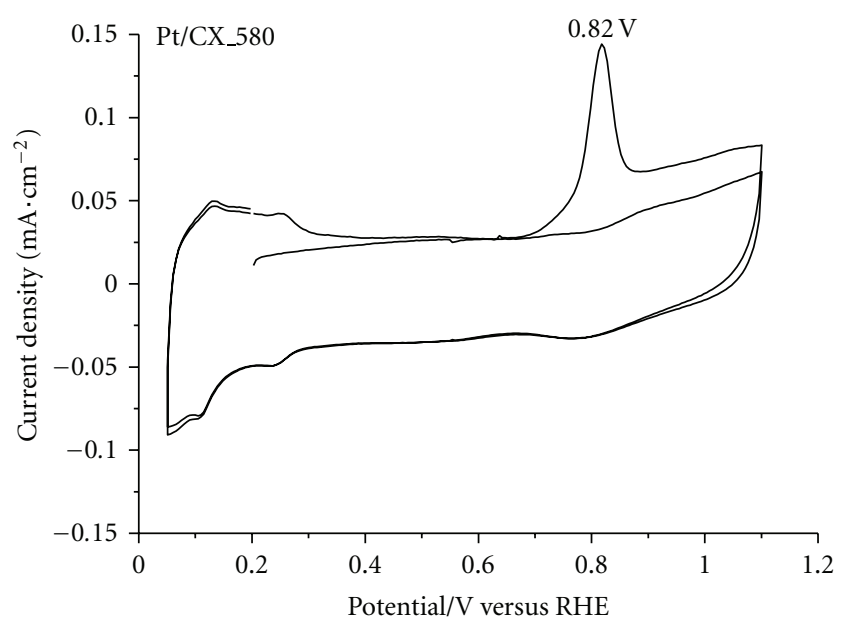

(b)

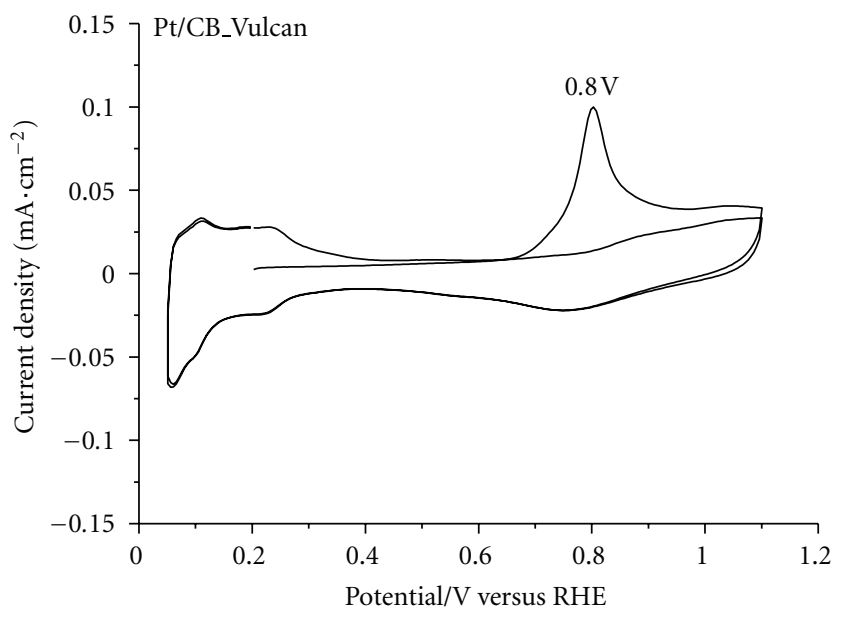

(d)

FIgURe 3: Cyclic voltammograms during CO stripping for Pt catalysts assayed in a $0.5 \mathrm{M} \mathrm{H}_{2} \mathrm{SO}_{4}$ solution. Scan rate $v=0.02 \mathrm{~V} / \mathrm{s}$.

that the capacitive behaviour is more apparent for the catalysts supported on the carbon xerogels than in the case of the one prepared using Vulcan XC-72 R or for Pt/E-TEK commercial catalysts, as previously reported in [31]. In this sense, the more developed textural properties (higher surface area) of the carbon xerogels employed as supports favours the capacitive behaviour of the catalysts.

The activity of the electrocatalysts towards the oxidation of methanol was studied by means of cyclic voltammetry, in a deaerated $2 \mathrm{M} \mathrm{CH}_{3} \mathrm{OH}+0.5 \mathrm{M} \mathrm{H}_{2} \mathrm{SO}_{4}$ solution at room temperature. Onset potentials and peak current densities measured obtained from the cyclic voltammograms (Figure 4) are shown in Table 3. Main differences can be observed at the sight of the current densities measured. While current densities are quite similar for catalysts prepared using CX_550, CX_580, and CB_Vulcan as supports, considerably lower current densities were determined for the commercial catalyst Pt/E-TEK.

The specific activity increases as a function of particle size [36]. Pt/CX_550 presents the higher particle size, but on the contrary does not present the higher specific activity.
On the other hand, Watanabe et al. found that the specific activity for methanol oxidation on a carbon-supported $\mathrm{Pt}$ electrocatalyst does not change for a particle size above $2 \mathrm{~nm}$ (Pt fcc structure); thus, the mass activity increases as the dispersion of the metal phase is increased [37]. In the case of our Pt/CXs catalysts, Pt catalyst prepared using the carbon xerogel synthesized at a higher $\mathrm{pH}$ shows a higher catalytic activity, which may be due to its better metal phase dispersion, when compared to the Pt catalyst prepared using the carbon xerogel synthesized at a lower $\mathrm{pH}$, that presents a higher particle size.

When comparing Pt/CX_580 with Pt/CB_Vulcan, with similar Pt crystal sizes (4.5 versus 4.0), Pt/CX_580 shows a slightly higher specific activity. In this case, the nature of the support may have some kind of positive influence on this parameter, presumably in terms of diffusion, since the CO stripping studies do not show, as explained before, a preferential surface structure for platinum independent of the carbon support. Carbon xerogel possess a highly developed mesopore structure (high pore volume and average pore size), what favours the diffusion of reactants towards $\mathrm{Pt}$ 


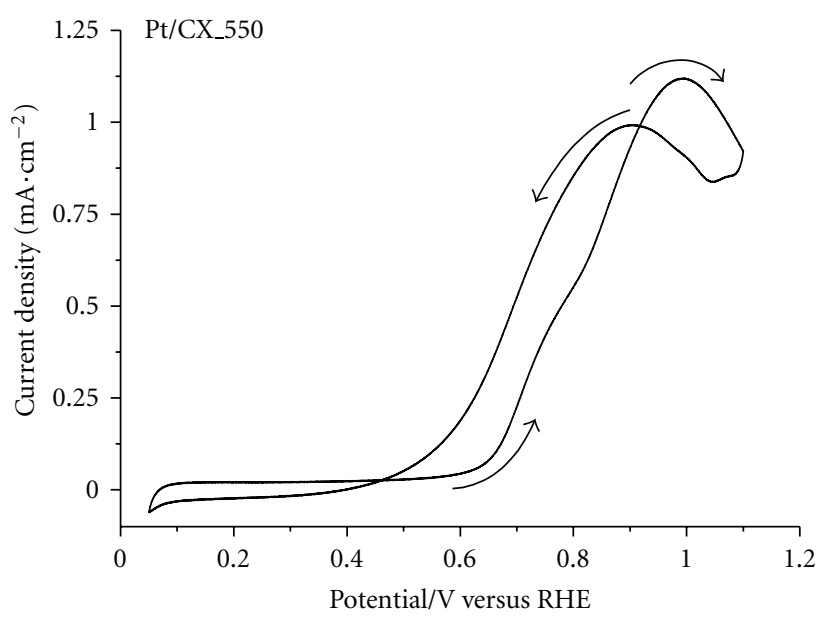

(a)

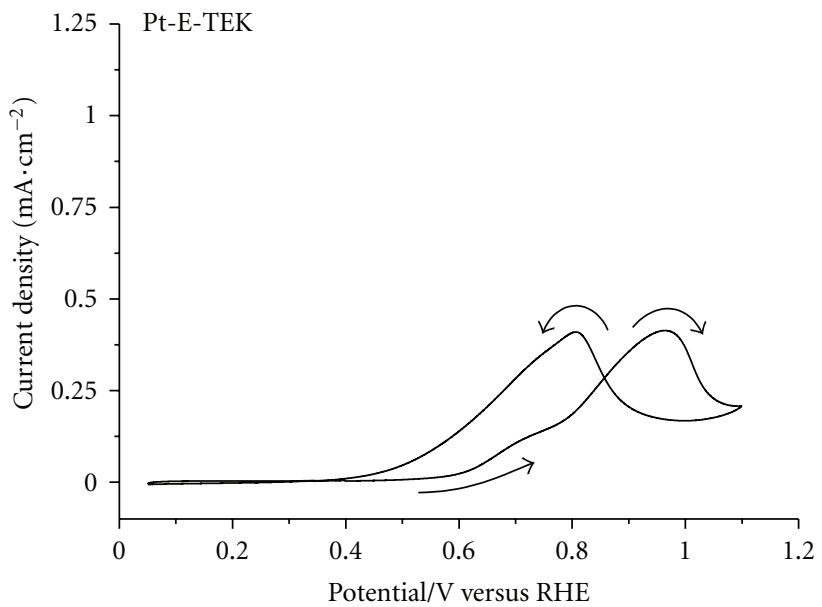

(c)

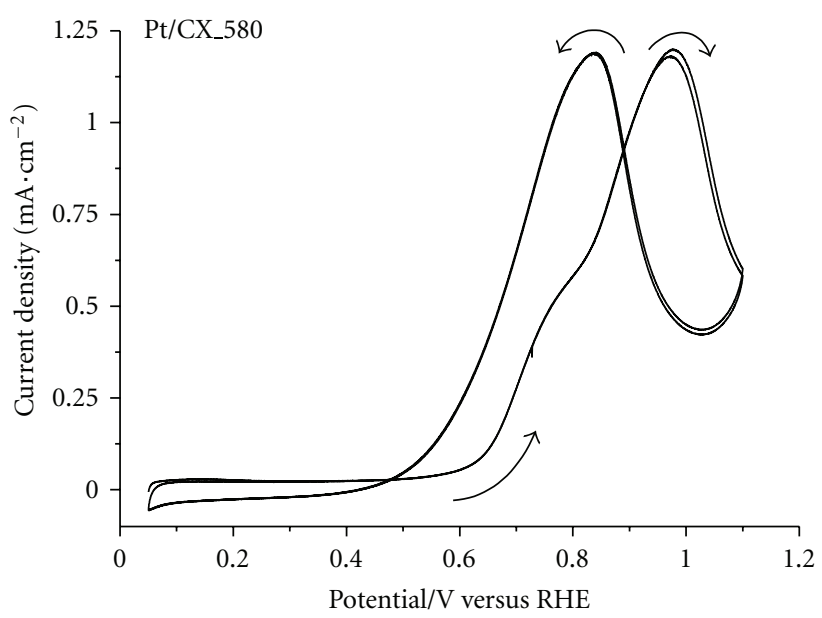

(b)

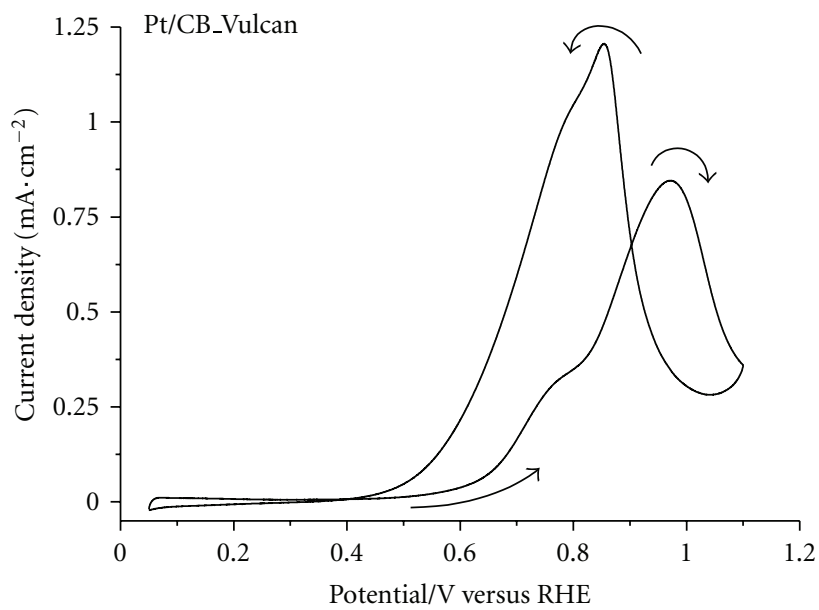

(d)

Figure 4: Cyclic voltammograms for the electrooxidation of methanol in a $2 \mathrm{M} \mathrm{CH}_{3} \mathrm{OH}+0.5 \mathrm{M} \mathrm{H}_{2} \mathrm{SO}_{4}$ solution at Pt catalysts and Pt-ETEK. Scan rate $v=0.02 \mathrm{~V} / \mathrm{s}$.

TABle 3: Onset and peak potentials extracted from methanol oxidation cyclic voltammetries measured for both the synthesised and commercial catalysts.

\begin{tabular}{lccc}
\hline Catalyst & $\begin{array}{c}\text { Onset } \\
\text { potential/V } \\
\text { versus RHE }\end{array}$ & $\begin{array}{c}\text { Forward } \\
\text { anodic } \\
\text { peak/mA cm }\end{array}$ & $\begin{array}{c}\text { Reverse anodic } \\
\text { peak/mA cm }\end{array}$ \\
\hline Pt/CX_550 & 0.53 & 1.13 & 1.00 \\
Pt/CX_580 & 0.51 & 1.24 & 1.21 \\
Pt/CB_Vulcan & 0.49 & 0.86 & 1.23 \\
Pt-E-TEK & 0.48 & 0.43 & 0.42 \\
\hline
\end{tabular}

particles. In fact, the most active catalyst towards methanol oxidation reaction is Pt/CX_580, which support presents the best textural features among the studied materials in this work.

Methanol electrooxidation chronoamperometric measurements presented in Figure 5 show that Pt/CX_580 reaches initially the highest current density, what it may be favoured due to its enriched mesopore structure, favouring reactants diffusion. However, current density in the case of carbon xerogels supported catalysts decay uniformly with time, which is not the case of carbon-black-supported catalysts. This effect may be attributed to the accumulation of intermediate products that will be clarified with further spectroelectrochemical studies.

\section{Conclusions}

With the aim of analyzing the influence of the $\mathrm{pH}$ during carbon xerogel synthesis in their final textural properties and behaviour as supports in the preparation of $\mathrm{Pt}$ electrocatalysts, two different carbon xerogels were synthesized adjusting each corresponding initial solution to different $\mathrm{pH}$ values, namely, 5.5 and 5.8. The determination of their textural and morphological properties by means of nitrogen physisorption evidenced notably higher development of mesoporosity and more compact structure (studied by means of scanning electron microscopy) in the case of 


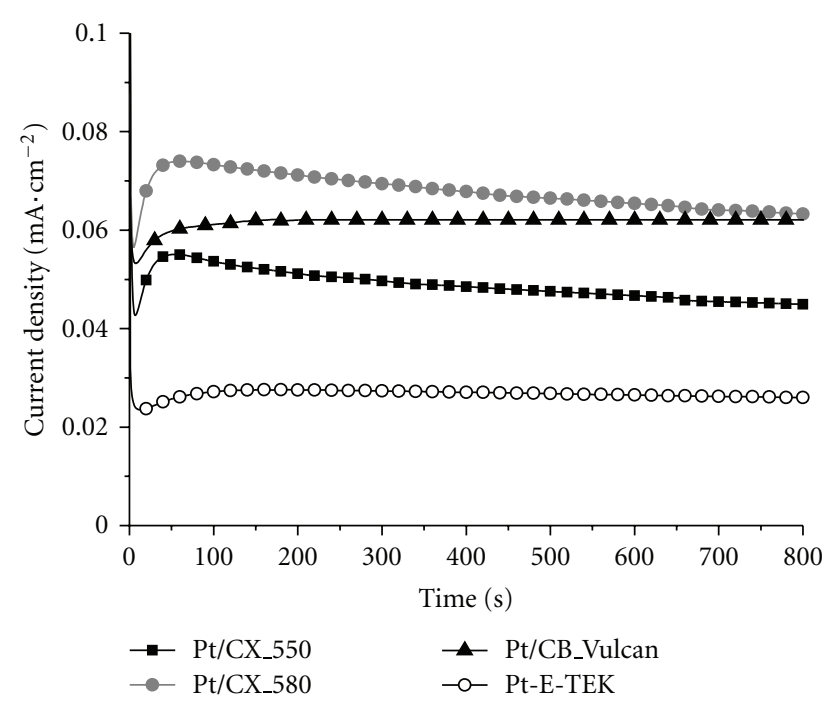

FIgure 5: Current density-time curves recorded in a $2 \mathrm{M} \mathrm{CH}_{3} \mathrm{OH}$ $+0.5 \mathrm{M} \mathrm{H}_{2} \mathrm{SO}_{4}$ solution at $E=0.60 \mathrm{~V}$ versus RHE for Pt-supported and Pt-E-TEK catalysts.

the carbon xerogel synthesized at the highest $\mathrm{pH}$. Both materials show higher surface areas than those measured for Vulcan XC-72R; however, the carbon xerogel synthesized at the lower $\mathrm{pH}$ showed an important contribution of microporosity and lower amount of mesopores than this commercial carbon black. Pt catalysts were synthesized using the carbon xerogels prepared and Vulcan XC-72R as supports. XRD analysis showed smaller Pt crystallite size in the case of the carbon xerogel possessing a more developed porous structure, that is, the one synthesized at higher initial $\mathrm{pH}$. More developed porosity, concretely abundance of mesopores, resulted in an optimized impregnation of the carbon surface, contributing to a more adequate active-phase dispersion.

Electrochemical characterization showed similar tolerance towards CO poisoning for the catalysts prepared using the synthesized carbon xerogels and the analogous catalysts prepared using Vulcan XC-72R as supports. Among carbon xerogels, slight differences were observed with small contributions to $\mathrm{CO}$ oxidation at more negative potentials.

Methanol electrooxidation studied by voltamperometric analyses showed that current densities obtained were considerably higher in the case of the carbon-xerogel-based catalysts and the Pt/CB_Vulcan catalyst, compared to the commercial Pt/E-TEK. Pt/CX_580 showed the highest specific activity which may be a combination of both adequate metal dispersion and a highly developed mesoporous structure, that may favour reactants diffusion towards reactive sites.

In fact, methanol chronoamperometry showed higher initial current density in this case, although electrocatalytic activity soon decreased with time reaching similar current density values than $\mathrm{CB}_{-}$Vulcan supported catalyst. At the beginning of the curves, the higher catalytic activity of the Pt/CX_580 catalyst may be due to diffusional effects that are favoured for $\mathrm{Pt} / \mathrm{CX}$ catalyst (given its higher mesopore structure when compared to Vulcan).
Nevertheless, at the sight of the results obtained in this work, it can be concluded that the more developed and mesopore-enriched porous structure of the carbon xerogel synthesized at a higher initial $\mathrm{pH}$ resulted in a more optimal utilization of the active phase and in an enhanced and promising catalytic activity in the electrooxidation of methanol, in comparison to analogous catalysts prepared using Vulcan carbon black as support and to commercially available Pt catalysts.

\section{Acknowledgments}

The authors wish to thank "FEDER" and the Spanish MICINN for financial support MAT2008-06631-C03-01. M. E. Gálvez is indebted to the Spanish Ministry of Science and Innovation for its "Juan de la Cierva" postdoctoral grant.

\section{References}

[1] S. Wasmus and A. Küver, "Methanol oxidation and direct methanol fuel cells: a selective review," Journal of Electroanalytical Chemistry, vol. 461, no. 1-2, pp. 14-31, 1999.

[2] J. R. C. Salgado, E. Antolini, and E. R. Gonzalez, "Structure and activity of carbon-supported Pt-Co electrocatalysts for oxygen reduction," Journal of Physical Chemistry B, vol. 108, no. 46, pp. 17767-17774, 2004.

[3] E. Teliz, V. Díaz, R. Faccio, A. W. Mombru, and F. Zinola, "The electrochemical development of Pt(111)stepped surfaces and its influence on methanol electrooxidation," International Journal of Electrochemistry, vol. 2011, Article ID 289032, 9 pages, 2011.

[4] Z. Cui, C. Liu, J. Liao, and W. Xing, "Highly active PtRu catalysts supported on carbon nanotubes prepared by modified impregnation method for methanol electro-oxidation," Electrochimica Acta, vol. 53, no. 27, pp. 7807-7811, 2008.

[5] J. L. Figueiredo, M. F. R. Pereira, P. Serp, P. Kalck, P. V. Samant, and J. B. Fernandes, "Development of carbon nanotube and carbon xerogel supported catalysts for the electro-oxidation of methanol in fuel cells," Carbon, vol. 44, no. 12, pp. 2516-2522, 2006.

[6] D. Sebastián, J. C. Calderón, J. A. González-Expósito et al., "Influence of carbon nanofiber properties as electrocatalyst support on the electrochemical performance for PEM fuel cells," International Journal of Hydrogen Energy, vol. 35, no. 18, pp. 9934-9942, 2010.

[7] L. Calvillo, M. Gangeri, S. Perathoner, G. Centi, R. Moliner, and M. J. Lázaro, "Effect of the support properties on the preparation and performance of platinum catalysts supported on carbon nanofibers," Journal of Power Sources, vol. 192, no. 1, pp. 144-150, 2009.

[8] L. Calvillo, M. J. Lázaro, E. García-Bordejé et al., "Platinum supported on functionalized ordered mesoporous carbon as electrocatalyst for direct methanol fuel cells," Journal of Power Sources, vol. 169, no. 1, pp. 59-64, 2007.

[9] N. Job, M. F. R. Pereira, S. Lambert et al., "Highly dispersed platinum catalysts prepared by impregnation of texturetailored carbon xerogels," Journal of Catalysis, vol. 240, no. 2, pp. 160-171, 2006.

[10] P. V. Samant, J. B. Fernandes, C. M. Rangel, and J. L. Figueiredo, "Carbon xerogel supported Pt and Pt-Ni catalysts for electro-oxidation of methanol in basic medium," Catalysis Today, vol. 102-103, pp. 173-176, 2005. 
[11] H. J. Kim, W. I. Kim, T. J. Park, H. S. Park, and D. J. Suh, "Highly dispersed platinum-carbon aerogel catalyst for polymer electrolyte membrane fuel cells," Carbon, vol. 46, no. 11, pp. 1393-1400, 2008.

[12] J. Marie, S. Berthon-Fabry, P. Achard, M. Chatenet, A. Pradourat, and E. Chainet, "Highly dispersed platinum on carbon aerogels as supported catalysts for PEM fuel cell-electrodes: comparison of two different synthesis paths," Journal of Non-Crystalline Solids, vol. 350, pp. 88-96, 2004.

[13] N. Job, J. Marie, S. Lambert, S. Berthon-Fabry, and P. Achard, "Carbon xerogels as catalyst supports for PEM fuel cell cathode," Energy Conversion and Management, vol. 49, no. 9, pp. 2461-2470, 2008.

[14] X. Yu and S. Ye, "Recent advances in activity and durability enhancement of $\mathrm{Pt} / \mathrm{C}$ catalytic cathode in PEMFC. Part I. Physico-chemical and electronic interaction between $\mathrm{Pt}$ and carbon support, and activity enhancement of Pt/C catalyst," Journal of Power Sources, vol. 172, no. 1, pp. 133-144, 2007.

[15] C. Arbizzani, S. Beninati, E. Manferrari, F. Soavi, and M. Mastragostino, "Cryo- and xerogel carbon supported PtRu for DMFC anodes," Journal of Power Sources, vol. 172, no. 2, pp. 578-586, 2007.

[16] R. W. Pekala, "Organic aerogels from the polycondensation of resorcinol with formaldehyde," Journal of Materials Science, vol. 24, no. 9, pp. 3221-3227, 1989.

[17] H. T. Gomes, P. V. Samant, P. Serp, P. Kalck, J. L. Figueiredo, and J. L. Faria, "Carbon nanotubes and xerogels as supports of well-dispersed Pt catalysts for environmental applications," Applied Catalysis B, vol. 54, no. 3, pp. 175-182, 2004.

[18] N. Job, A. Théry, R. Pirard et al., "Carbon aerogels, cryogels and xerogels: influence of the drying method on the textural properties of porous carbon materials," Carbon, vol. 43, no. 12, pp. 2481-2494, 2005.

[19] M. Kim, J. N. Park, H. Kim, S. Song, and W. H. Lee, "The preparation of $\mathrm{Pt} / \mathrm{C}$ catalysts using various carbon materials for the cathode of PEMFC," Journal of Power Sources, vol. 163, no. 1, pp. 93-97, 2006.

[20] B. Liu and S. Creager, "Carbon xerogels as Pt catalyst supports for polymer electrolyte membrane fuel-cell applications," Journal of Power Sources, vol. 195, no. 7, pp. 1812-1820, 2010.

[21] N. Job, M. F. R. Pereira, S. Lambert et al., "Highly dispersed platinum catalysts prepared by impregnation of texturetailored carbon xerogels," Journal of Catalysis, vol. 240, no. 2, pp. 160-171, 2006.

[22] S. A. Al-Muhtaseb and J. A. Ritter, "Preparation and properties of resorcinol-formaldehyde organic and carbon gels," Advanced Materials, vol. 15, no. 2, pp. 101-114, 2003.

[23] E. J. Zanto, S. A. Al-Muhtaseb, and J. A. Ritter, "Sol-gel-derived carbon aerogels and xerogels: design of experiments approach to materials synthesis," Industrial and Engineering Chemistry Research, vol. 41, no. 13, pp. 3151-3162, 2002.

[24] N. Mahata, M. F. R. Pereira, F. Suárez-García, A. MartínezAlonso, J. M. D. Tascón, and J. L. Figueiredo, "Tuning of texture and surface chemistry of carbon xerogels," Journal of Colloid and Interface Science, vol. 324, no. 1-2, pp. 150-155, 2008.

[25] C. Lin and J. A. Ritter, "Effect of synthesis PH on the structure of carbon xerogels," Carbon, vol. 35, no. 9, pp. 1271-1278, 1997.

[26] L. Zubizarreta, A. Arenillas, A. Domínguez, J. A. Menéndez, and J. J. Pis, "Development of microporous carbon xerogels by controlling synthesis conditions," Journal of Non-Crystalline Solids, vol. 354, no. 10-11, pp. 817-825, 2008.
[27] N. Job, R. Pirard, J. Marien, and J. P. Pirard, "Porous carbon xerogels with texture tailored by $\mathrm{pH}$ control during sol-gel process," Carbon, vol. 42, no. 3, pp. 619-628, 2004.

[28] A. S. Arico, S. Srinivasan, and V. Antonucci, "DMFCs: from fundamental aspects to technology development," Fuel Cells, vol. 1, pp. 133-161, 2001.

[29] S. Srinivasan, Fuel Cells: From Fundamentals to Applications, Springer, New York, NY, USA, 2006.

[30] V. S. Bagotzky and Y. B. Vassilyev, "Mechanism of electrooxidation of methanol on the platinum electrode," Electrochimica Acta, vol. 12, no. 9, pp. 1323-1343, 1967.

[31] C. Alegre, L. Calvillo, R. Moliner et al., "Pt and PtRu electrocatalysts supported on carbon xerogels for direct methanol fuel cells," Journal of Power Sources, vol. 196, no. 9, pp. 42264235, 2011.

[32] B. Beden, C. Lamy, N. R. de Tacconi, and A. J. Arvia, "The electrooxidation of CO: a test reaction in electrocatalysis," Electrochimica Acta, vol. 35, no. 4, pp. 691-704, 1990.

[33] J. M. Feliu, J. M. Orts, A. Femandez-Vega, A. Aldaz, and J. Clavilier, "Electrochemical studies in sulphuric acid solutions of adsorbed CO on Pt (111) electrodes," Journal of Electroanalytical Chemistry, vol. 296, no. 1, pp. 191-201, 1990.

[34] G. García, J. A. Silva-Chong, O. Guillén-Villafuerte, J. L. Rodríguez, E. R. González, and E. Pastor, "CO tolerant catalysts for PEM fuel cells. Spectroelectrochemical studies," Catalysis Today, vol. 116, no. 3, pp. 415-421, 2006.

[35] J. S. Ye, X. Liu, H. F. Cui, W. D. Zhang, F. S. Sheu, and T. M. Lim, "Electrochemical oxidation of multi-walled carbon nanotubes and its application to electrochemical double layer capacitors," Electrochemistry Communications, vol. 7, no. 3, pp. 249-255, 2005.

[36] J. A. Poirier and G. E. Stoner, "Microstructural effects on electrocatalytic oxygen reduction activity of nano-grained thinfilm platinum in acid media," Journal of the Electrochemical Society, vol. 141, no. 2, pp. 425-430, 1994.

[37] M. Watanabe, S. Saegusa, and P. Stonehart, "High platinum electrocatalyst utilizations for direct methanol oxidation," Journal of Electroanalytical Chemistry, vol. 271, no. 1-2, pp. 213-220, 1989. 


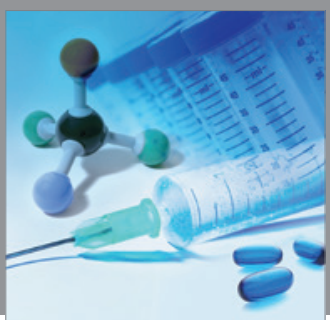

International Journal of

Medicinal Chemistry

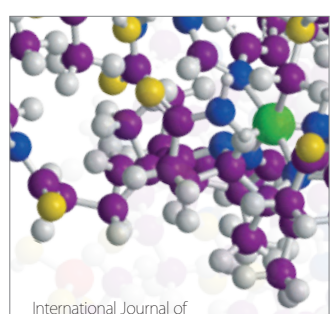

Carbohydrate Chemistry

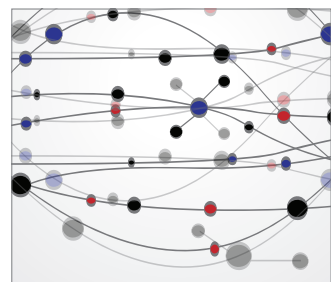

The Scientific World Journal
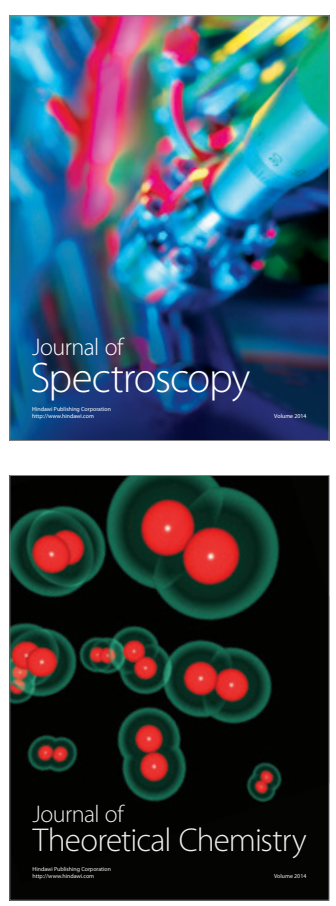
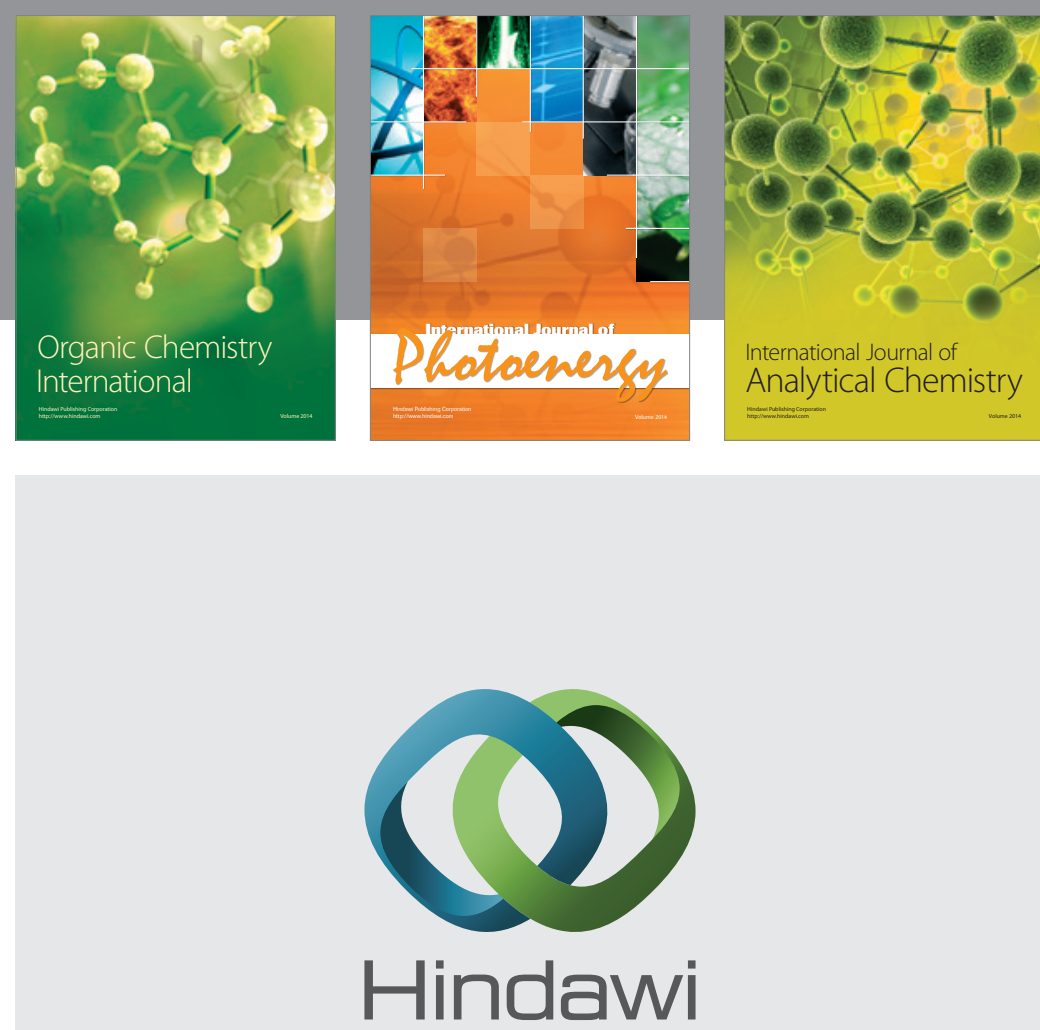

Submit your manuscripts at

http://www.hindawi.com
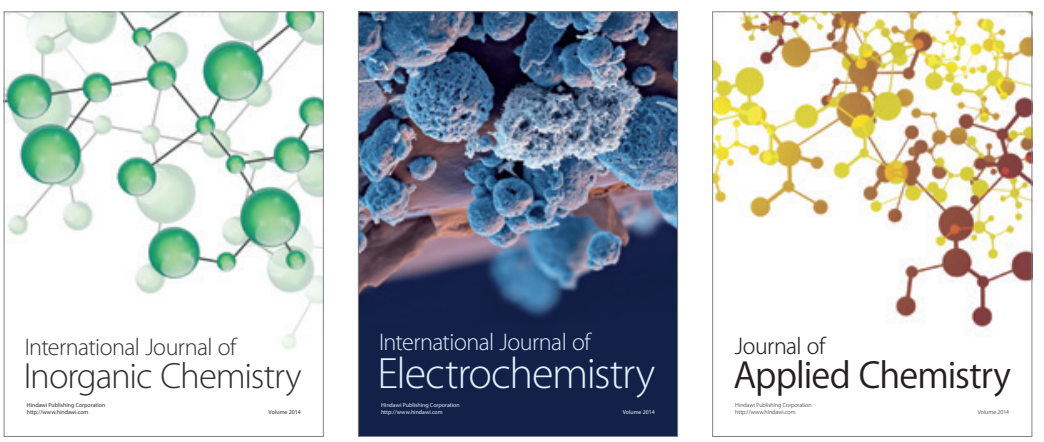

Journal of

Applied Chemistry
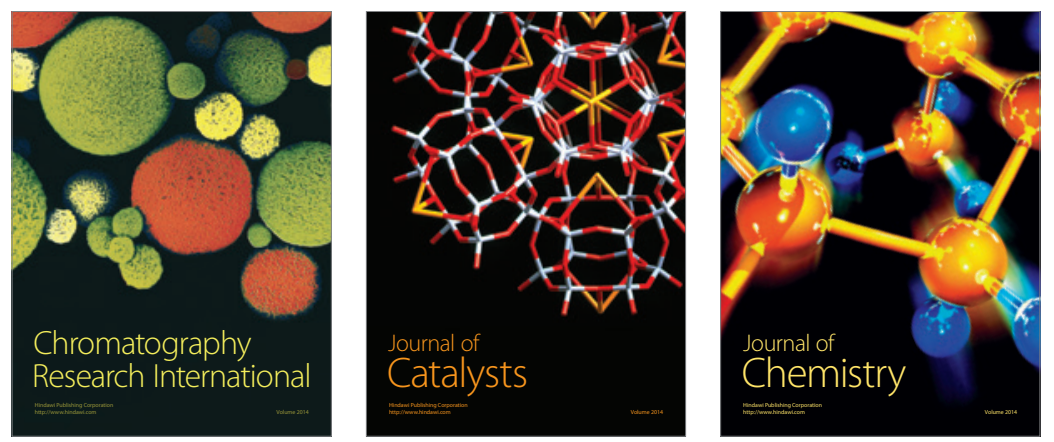
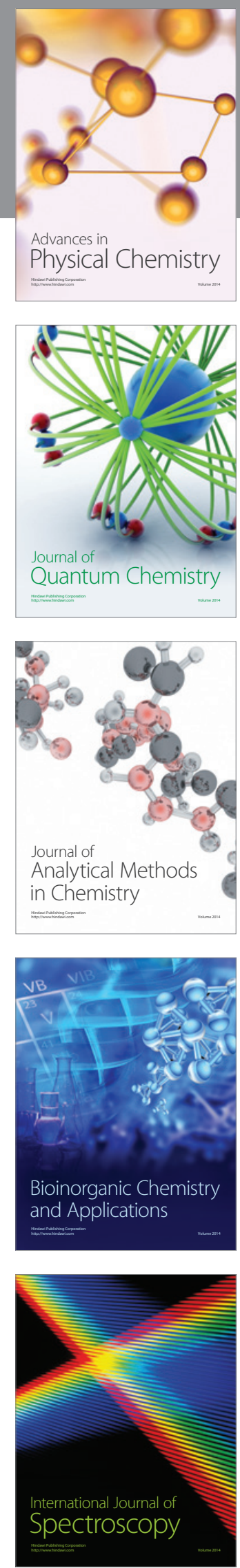